\title{
A Study of Visual Poem "in Just-" from the Perspective of Multimodal Discourse Analysis
}

\author{
Xinmei Wang \\ School of Foreign Languages, Shandong University of Finance and Economics, Shandong, China \\ Email: wangxinmei010@sina.com
}

\begin{abstract}
Just-" is one of the best-written poems by American modernism poet e. e. cummings. "in Just-" helps the reader visually see the transformation from reality to illusion and aurally hear the conversion of time and space, and it illustrates its unique visual and aural effects to further the theme of spring. This paper attempts to analyze the linguistic and typographical aspects of this visual poem "in Just-" from the perspective of multimodal discourse analysis, which is developed from the theoretical framework of Halliday's functional linguistics. The aim of the study is to explore possibilities of analyzing and interpreting e. e. cummings' or other authors' visual poems.
\end{abstract}

Index Terms - typography, visual poem, multimodal discourse analysis, e. e. cummings

\section{INTRODUCTION}

Edward Estlin Cummings (1894-1962), abbreviated e. e. cummings, was the representative of American modern experimental poets as well as painters in modernism. He is recognized as an avant-garde in his idiosyncratic poetic expressions. He published 900 poems during his whole life. As one of modern poets, he experimentally created many visual poems. Cummings reflects the harmony of poems and paintings in his work.

The previous study places emphasis on the particular techniques of semantic, grammatical, lexical and graphological deviations skillfully designed by e. e. cummings, through which his verses are foregrounded and produce strong visual impression upon the reader (Xu Yanping Yangyue, 2005; Zhang Xuhong, 2010; Xia Riguang, 2005). Wang Yin (1999) points out that there are iconic relationships between the writing form of some letters or words and the meaning the letters or the words express. The deviated expressions and structure in his poetry reveal strong love, interior happiness, pains, special sense of humor and penetrating satire. As his deviated verses contain various kinds of possible meanings, the reader is given enormous space of imagination so as to find out new meaning in the creation of a poetic discourse.

Along with the development of modern technology, more and more multimedia technologies have been employed in the analysis of poems. This paper proposes tentatively a model of multimodal approach to visual poems based upon the theory of systemic functional grammar and the theory of multimodality. It is analyzed following a procedure in the study: multimodal decomposition, mono-modal meaning construction, and multimodal meaning integration.

\section{VisUal POETRY}

Poetry is expected to project images in mind. It translates any text into a series of images by looking up the words on the internet, and projecting the most relevant results as a slide show. Visual poetry is poetry in which the typographical arrangement of words is as important in conveying the intended effect as the conventional elements of the poem, such as meaning of words, rhythm, and rhyme, etc (Wang Hongyang, 2007). Visual poetry uses the page as a canvas to visually represent the themes, subjects, or sentiments of words in a variety of shapes and forms. The beauty of the visual format lies in the poet's ability to mark, prescribe, or record process; the replication of shape; or the simulation of movement. It can also present the material in a way that leads to other meanings or implications that aren't reflected in the words themselves.

Studying the special effects on the visual poem can make the readers totally understand the deeper meanings of the poems. In this poem "in Just-", Cummings extols spring, which symbolizes the worship of nature, childish innocence and hope, contradicting the absence of faith, adults' decadence and despair prevailing in the modern society.

\section{The TheORETICAL Foundation OF ThIS StUdY}

Discourse analysis is concerned with language and the relationship between language and contexts in which it is used. But with the development of technology, discourse analysis has gone through a serious of changes. At one time, language is the most important semiotic system. But recently this dominance of monomodality has begun to change. So far the diccourse analysis is largely constrained to language itself, attention has been focused on language system and semantic structure and their relation to cognition. While other ways of meaning producing like images, sounds, colors are ignored. This has made discourse analysis far from comprehensive and exhaustive. Multimodal discourse analysis starting in 90 s of the last century in the west could solve this problem. 
The theoretical basis of this paper should be Halliday's SFG (Systemic Functional Grammar), and Kress and Van Leeuwen's Visual Grammar.

The 21 st century is teemed with ever more mixed and remixed images, writing, layout, sound, gesture, speech, etc. Multimodality looks beyond language and examines these multiple modes of communication and meaning making.

MDA (Multimodal Discourse Analysis) is a kind of discourse analysis which has been popular among the western countries for the past decade (Kress \& Leeuwen, 2006). Multimodality means "the use of several semiotic modes in the design of a semiotic product or event together with the particular way in which these modes are combined---they may for instance reinforce each other..., fulfill complement roles..., or be hierarchically ordered"(Kress \& Van Leeuwe, 2001, p. 20). Multimodal discourse refers to those in which at least two semiotic modes interact to construct meaning. Almost all discourse are multimodal. Van Leeuwen (2006) argues that even the verbal text itself is multimodal because the typography and typeface of the verbal are also semiotic modes. Multimodal discourse analysis is introduced to emphasize the importance of taking into consideration of semiotics other than language-in-use, such as the sound, images, colors and typographies. Researchers found that it was impossible to study discourse analysis solely from the perspective of pure linguistic level because non-linguistic modalities also can express the meaning of the speaker such as sound effect, gestures, facial expressions and so on. Under these circumstances, it requires combining language, visual images and sounds to achieve the best communicative effect.

The systemic functional approach to multimodal discourse analysis is concerned with the theory and practice of analyzing meaning arising from the use of multiple semiotic resources in discourses which range from written, printed and electronic texts to material lived-in reality.

In Thibault's (2000) conception, multimodality is defined as "the diverse ways in which multiple semiotic resources (language, visual images or sound) are both co-deployed and co-contextualized in the making of a text -specified meaning"(p. 312).

Multimodality provides the means to describe a practice or representation in all its semiotic complexity and richness.

According to Hallidayan three metafunctions of the language: the experiential, the interpersonal and the textual, Kress and Van Leeuwen (2006) sets up a basic framework for visual analysis, "assigning Representational, Interactive and Compositional meanings to images" (Moya \& Pinar, 2008, p. 1603-1604), which has already been the popular method of social semiotic analysis of visual communication and has been listed respectively in the following Table:

\begin{tabular}{|l|l|}
\hline Visual Grammar & SFL \\
\hline Representational & Ideational \\
\hline Interactive & Interpersonal \\
\hline Compositional & Textual \\
\hline
\end{tabular}

Multimodal discourse analysis suggests that discourses exist as multimodal forms rather than mono-modal forms. They use sounds, visual images, animations and colors. Multimodality discourse analysis, which started in 1990s in the western countries, provides a more comprehensive perspective of analyzing different texts. Therefore, this paper is to analyze visual poem under the theoretical framework of multimodal discourse analysis.

\section{Multimodal Analysis of Visual Poem}

Bemsen (2002) points out that multimodality can be divided into two or more mono modes. To have a deeper analysis of multimodality discourse, we may firstly decompose the different modes into separate ones.

The analysis of visual poems from the perspective of multimodal analysis follows the following steps: multimodal decomposition, mono-modal meaning construction, and multimodal meaning integration. The following is the poem "in Just-".

in Just-

in Just-

spring when the world is mud-

luscious the little

lame balloonman

whistles far and wee

and eddieandbill come

running from marbles and

piracies and it's

spring

when the world is puddle-wonderful

the queer

old balloonman whistles 


\begin{abstract}
far and wee
and bettyandisbel come dancing

from hop-scotch and jump-rope and

it's

spring

and

the

goat-footed

balloonMan whistles

far

and

wee

The poem displays that a group of children (boys and girls), are playing games joyfully in the wet mud in an early spring. At this time, they hear a balloonman coming, selling his colorful balloons by whistling. All the children, attracted by the balloons, run together toward the old man, only to find him goat-footed.
\end{abstract}

A. Verbal Mode of "in Just-"

Verbal modes refer to the semiotics like words, syntax, and phonology in text. From this perspective, "in Just" is composed of 23 lines, and seemingly one sentence. Systematic function grammar is of three meta-functions: ideational function, interpersonal function and textual function.

1. Ideational Function

Ideational function refers to the speaker's experience of the real world, including the inner world of his own consciousness. Halliday (1985) divides the ideational function into two functions: the logical and the experiential metafunctions. The logical metafunction refers to the grammatical resources for building up grammatical units into complexes, for instance, for combining two or more clauses into a clause complex. The experiential function refers to the grammatical resources involved in construing the flux of experience through the unit of the clause.

"in Just-" tells us that it's that day in May when the sun starts shining for the first time in weeks and everybody heads out to the park. The story's pretty simple: spring has sprung. Everything's growing and all-around delightful. The kids, in fact, jump for joy when the man selling balloons starts to whistle. Clowns (and other balloon-selling folk) have gotten a bad rap for being scary and creepy, but this guy seems to be all right. At the very least, he gets the kiddies to come running to him.

2. Interpersonal Function

According to Halliday (1985), the interpersonal function represents the speaker's meaning potential as an intruder. It is the participatory function of language. It is through language that the speaker intrudes himself into the context of situation. He expresses his own attitudes and judgments and seeks to influence the attitudes and behavior of others. The interpersonal function expresses the role relationships associated with the situation. We gain much of our sense of identity, of who and what we are, from our relationships both with animate and inanimate things, and language is an essential part of that personalizing process.

The present tense runs through the whole poem, which indicates the general descriptions, and draws home the point that he was describing what he saw at that moment. As for the judgment and evaluation of the poet, from line 11 to 13 , he used the word "queer", we can infer that this balloon-selling guy is totally not fitting in with the rest of the spring-themed thing, but he does seem to be driving all of the action. He's old and strange, he seems ominous. We do finally get one tiny hint about who this balloonman might be in these last lines. Besides goats, a few famous mythical creatures had goat's feet. Satyrs, in particular, are often depicted as creatures that are human in appearance from the waist up and goat-like from the waist down.

3. Textual Function

The textual meta-function relates to mode; the internal organization and communicative nature of a text. This comprises textual interactivity, spontaneity and communicative distance. In this poem, the author adopted the paralleled thematic structure, for example, "the world", "the little lame balloonman" and "eddieandbbill" are the theme of each separated clause. All of these present to us the coming of spring. The focus of the information of this poem is Just-spring.

\title{
B. Visual Mode of "in Just-"
}

The shape of a poem may be designed in an unconventional way so that it may be suggestive of a certain literary theme. 
"in Just-" helps the reader visually see the transformation from reality to illusion and aurally hear the conversion of time and space, and it demonstrates its unique visual and aural effects to further the theme of spring. Cummings extols spring, which symbolizes the worship of nature, childish innocence and hope, contradicting the absence of faith, adults' decadence and despair prevailing in the modern society.

1. Representational Meaning

Representational meaning can be achieved through visual construction of the nature of events, the objects and participants involved and the circumstances in which they occur.

This poem is arranged in vertical order and composed of four stanzas. We can find the perfect combination of open and close form in this poem. Cummings adopted the non-traditional techniques like capitalization, decapitalization, blank spaces, print and arrangement of lines in poem to express the theme of the poem.

The most striking in this poem is perhaps the fact that there is no title. Or "in Just-" serves double-duty: it's both adopted title and first line. Cummings makes up a hyphenated word (Just-spring) and then splits it up, putting half into the title and half into the first line. It is only one clause which runs over the whole poem. This may show that poet intends the poem to be read as a whole and places emphasis on the unity of the discourse. The important effect created is the arousal of the readers' expectation and interest. Taking a close look at the whole poem, we find that every line of the poem, in fact, creates a pulling-forward effect, though there may be differences in the degrees of strength.

Actually, Cummings often adopts capitalization in accordance with his thematic ideas. In "in Just-", the balloonman becomes balloonMan toward the end of the poem indicates a transmutation from childhood to adulthood. Emphasizing the "Man", Cummings is either pointing toward the hidden sexual theme of the poem or toward the state of adulthood in general. Meanwhile, the capital in "Just" emphasizes a "spring which brings its own inevitable justice," and "in the earliest spring," or "in the only season ("just in spring") in which such things could possibly happen".

From above analysis, we can infer that the capitalization of a few words imply emphatic impression. With small letters set as the background, it creates a shift from one state to another. This linguistic form is equal to the structure of external objective world. Furthermore, this linguistic form can also reflect Cummings' individual experience---that of a being as a painter because the application of the lower case in most other words has dented the whole plane of the poem. And thus made the capitalized ones outstandingly striking. From this aspect, we can see that Cummings maps his painting knowledge onto his creation of poems, which proves that the structure of language reflects in some way the structure of individual experience.

2. Interactive function

Interactive meaning can be achieved through visual resources which construct the nature of relationships among speaker/listener, writer/reader, and viewer and what's viewed. Image in discourse could make a special relation between the contents of the image and readers, the image is interactive with readers and prompts the viewers which attitude they should hold to the represented things.

Spring is a young season. Children are young humans. We can call lower-case letters the baby version of upper-case alphabets. Everything in "in Just-" is young and vibrant except for the "old, lame" figure who serves as the central focus of the poem. How do youth and age interact? What sort of language can a poem create to express and embody youth? And exactly how bad is it to be old? The poet highlights all of these through the use of capitalized "Just", balloonMan and de-capitalized eddieandbill, bettyandisbel. The children in "in Just-" are so innocent that they don't even bother to be offended by the fact that their names are strung together in clumps of words. Only mature folks would get concerned about things as silly as self-identity.

This poem doesn't just lie on the page. It dances itself out, stretching into blank spaces and squeezing together in energetic word-clusters. What does a line that one contains one word look when it's next to lines full of text? As we realize, the way a poem looks can affect the way we hear it, as well. How does blank space sound? Do we pause whenever we get to a line break? Cummings teases his readers into thinking through formal problems that are quite a bit more complex than they might first appear.

"in Just-" positively revels in everything that's young and joyful. Of course, the appearance of a Pan-like balloonMan complicates this easy, breezy, beautiful relationship between innocent children and an innocence-filled world. Anyway, he plays in integral role in heralding spring. The arrival of the balloonMan seems to be one of the first signs that it is spring in the first place.

3. Compositional Meaning

Composition, relates the representational and interactive meanings of the image to each other through three interrelated system: information value; salience and framing. Compositional Meaning is concerned with the distribution of the information value or relative emphasis among elements of the text and image.

In 24 lines of this poem we can easily find three paralleled structures: line 3-5 (the little lame balloonman whistles far and wee), line 11-13 (the strange old balloonman whistles far and wee), line 19-24 (the goat-footed balloonMan whistles far and wee). The subject of each sentence creates special visual effect, and the predicate of each creates the same audio effect. All of these help the reader visually see the transformation from reality to illusion and aurally hear the conversion of time and space.

Another typical feature of this poem is the adaptation of blank spaces between words or lines and spreading of words across lines. In line 5 and line 13 "far" and "wee" are separated with each other. In the end of the poem, "far and wee" 
are arranged in three lines. On one hand, we slow down when we read each line. This spacing out of the words or lines mimics something growing. It's like those sped-up videos of a seed growing out of the ground. All of a sudden, it unrolls itself, lengthening into a long stalk. On the other hand, it may indicate the whistling sound disappear gradually.

We may also be attracted by the use of compound nouns: goat-footed; mud-luscious, puddle-wonderful; balloonman; eddieandbill; bettyandisbel. They are "nonce-formations".

The unusual compounds that Cummings use are suggestive of a "child's language": hence, mud-luscious (pleasant muddy) and puddle-wonderful (pleasant puddly), mud-luscious and puddle-wonderful evoke the joyful scenery---the children playing happily on the muddy ground after spring rain. By using words like "mud-luscious" and "puddle-wonderful", the poem seems to be bursting with descriptions of the way that a spring day in the park looks and feels and sounds and smells. And because the poem repeats itself several times it emphasizes the way that all the tiny details of the poem actually contribute to one overarching image: the park in spring. It's the world that is "mud-luscious" and "puddle-wonderful".

Line 6, 7, 14 and 15 may also arouse our attention, in which the names are merged into one another; eddieandbill (eddie and bill) (Eddie and Bill) and bettyandisbel (betty and isbele) (Elizabeth and Isabela). Eddie and bill come running and hand in hand. Eddie and bill are the names of two little boys, betty and isbel are those of two girls name, which have several meanings: the first, the de-capitalization of names demonstrates the boys are very little; the second, eddie and bill are merged into one word eddieandbill renders the cubic impression---the boys are running hand in hand. The effect here is to render the hustle, bustle and speed of the children as they come running to the summons of the whistle. They're also some of the longest lines of the poem. Length, like jammed-together words, creates a sense of fullness and action. Packed with very important activities, the world of little kids overflows with energy.

According to the context, the nonce-formation balloonman is the compounding of the words balloon and man which implies several meanings: Firstly, the man who sells balloons; secondly, the man looks like a mixture of balloons and man because there are a lot of balloons in his hands and over his hand; thirdly, balloonman is the symbol of spring. Balloons grant a profound impression of happiness and joy. Goatfooted/balloonMan makes readers associate it with Greek god Pan-Half-man, half-goat. Pan, God of music and play, is the symbol of spring. The capitalization of "Man" in balloonMan, on one hand, emphasizes that the man selling balloons is Pan-God of spring. On the other hand, it forms a contrast with eddieandbill and bettyandisbel.

\section{CONCLUSION}

From the above analysis we can find that the poem is quite unusual for the following aspects: first, the use of nonce words to save words and arouse readers' imagination, like mud-luscious, puddie-wonderful, balloonman, wee, eddyandbill, bettyandisbel, goat-footed. Second, the use of capitalization to reveal the age, relationship, manner of children, to make a shape contrast or to indicate the angle of observation, like in Just-, balloonMan. Third, the use of dash between words and lines to pause or to arouse readers' interest. Fourth, the use of irregular space to draw readers' attention, to indicate the distance and to reveal the children's reaction. The final effect by using these special means is to help readers to imagine and form a vivid moving picture in their mind while they are reading, evoke a joyful scenery (the children playing happily on the muddy ground after spring rain), reflect the harmony between poems and paintings and to better reveal the theme.

Conclusion can be obtained that a multimodal perspective emphasizes that language-in-use or any other mode does not occur on its own, but is integrated with and heavily dependent on others and the contributions of other meaning-making resources can not be ignored. According to the above analysis, each mode doesn't function separately but cooperate to articulate meanings. Multimodal approach is proved to be a systemic and a more thorough way in interpreting such poems. At the same time, it verifies the fact that multimodal analysis to language integrates language and language related resources. Therefore, it makes discourse interpretation more comprehensive and approximative.

\section{REFERENCES}

[1] Bemsen, N. O. (2002). Multimodality in Language and Speech Systems From Thoery to Designed Support Tool. In B. Granstorm, B. House D. \& Karlsson, L (eds). Multimodality in language and Speech Systems. Paris Kruwer Academic Publishers.

[2] Cureton, R. D. (1985). Visual Form in e. e. cummings': No Thanks. World \& Image 32.2, 3.

[3] Halliday, M.A.K. (1973). Explorations in the Functions of Language. London: Edward Arnold.

[4] Halliday, M.A.K. (1978). Language as Social Semiotic: The Social Interpretation o Language and Meaning. London: Edward Arnold.

[5] Halliday, M. A. K. (1985). An Introduction to Functional Grammar. London: Edward Arnold.

[6] Halliday, M.A.K. (1994). An Introduction to Functional Grammar. London: Edward Arnold.

[7] Kress G \& Leeuwen, T. (1990). Reading Images. Geelong: Dackin UP.

[8] Kress G \& Leeuwen, T. (1996). Reading Images. Burwood: Brown Prior Anderson.

[9] Kress G \& Leeuwen, T. (2006). Reading Images: The Grammar of Visual Design. London: Routledge.

[10] Leeuwen, T. V. (1999). Speech, Music and Sound. London: Macmillan.

[11] Leeuwen, T. V. (2005). Introducing Social Semiotics. London: Routledge. 
[12] Leeuwen, T. V. (2006). Towards a Semiotics of Typography. Informational Design 34. 5, 14.

[13] Widdowson H. G. (1992). Practical Stylistics. Oxford: Oxford University Press.

[14] Springer, S. H. (1967). The Poetics of E. E. Cummings. South Atlantic Bulletin 32. 4, 8-10.

[15] Wang Hongyang. (2007). Multimodal Analysis of E. E. Cummings' "l(a)". Foreign Language Study 28. 5, 22-26.

[16] Xia Riguang. (2005). Icon and Iconic Cohesion. Journal of Sichuan International Studies University 21. 3, 56-61.

[17] Xu Yanping, Yang Yue. (2005). Deviation and Foregrounding in E. E. Cummings' Poems. Journal of Xi'an International Studies University 13. 1, 1-7.

[18] Zhang Xuhong. (2012). On the Modality of the Visual Poem "Me up at does". Foreign Language Research 152. 1, 85-89.

Xinmei Wang, a College English teacher for English majors in Shandong University of Finance and Economics in Jinan, has been teaching English majors for more than eight years. The courses she has taught include Advanced English, Advanced English Writing, Reading, Listening, etc.. During this decade, she published several papers. Her research field is theoretical linguistics. 